Intravitreal

triamcinolone

\section{improves vision in eyes with chronic diabetic macular oedema refractory to laser photocoagulation}

AK Negi, SA Vernon, CS Lim and

K Owen-Armstrong controlled trials utilising varying doses of steroid are now required to define optimum treatment regimens.

Eye (2005) 19, 747-751. doi:10.1038/sj.eye.6701636;

published online 10 September 2004

Keywords: diabetic; macular oedema;

intravitreal; triamcinolone; steroid

\section{Introduction}

Diabetes remains the single most important cause of blindness in the working age population. Severe visual loss is usually a result of vitreous haemorrhage from proliferative disease, especially in type I diabetes. In patients with type II diabetes, however, maculopathy remains the most important cause for moderate visual loss with $29 \%$ patients developing macular oedema within 20 years of diabetes. ${ }^{1}$ More than half of such eyes will lose two or more lines of acuity after a follow-up of 2 years. The ETDRS demonstrated the effectiveness of focal laser photocoagulation in patients with diabetic macular oedema, ${ }^{2}$ compared with no treatment, however, in the diffuse variety with widespread capillary leakage response is typically poor to photocoagulation. ${ }^{3}$ Even though focal laser reduced moderate visual loss by $50 \%$ in the ETDRS, $12 \%$ of the treated eyes still lost 15 or more ETDRS letters at the 3 years. In contrast, less than $3 \%$ of treated eyes showed an improvement in vision of similar magnitude. Furthermore, laser treatment is essentially a destructive form of treatment with side effects and also possibility of iatrogenic visual loss with the expansion of laser scars with time. ${ }^{4}$
Department of Ophthalmology Eye and ENT Centre University hospital Nottingham, UK

Correspondence: SA Vernon Eye and ENT Centre University Hospital Nottingham NG7 2UH, UK Tel: + 441159249924 ext 43200

Fax: +44 1159709749

Received: 31 December 2003

Accepted: 13 April 2004 Published online:

10 September 2004

Presented in part at the Midland Ophthalmological Society meeting, 2003. 
The relative unresponsiveness to laser treatment of the diffuse variety of macular oedema especially in those with the involvement of the fovea, has prompted interest in alternative treatment modalities including pars plana vitrectomy, protein kinase-c inhibitors and the use of various long-acting and slow release corticosteroid preparations.

Intravitreal triamcinolone has been used for the treatment of proliferative vitreoretinopathy, choroidal neovascular membranes, postcataract surgery cystoid macular oedema, and macular oedena in uveitis. ${ }^{5-9}$

Recent reports cite the promising short-term results of the use of intravitreal triamcinolone in patients with diabetic macular oedema. ${ }^{10-12}$

We report the results of what we believe to be the first British prospective series of this treatment modality in patients with chronic long-standing diabetic macular oedema unresponsive to previous multiple laser treatment sessions.

\section{Material and methods}

All patients between June 2002 and May 2003 with persistent diffuse diabetic macular oedema and previous macular laser treatment who attended a specialist diabetic retinal clinic under the care of one of us (SAV, CSL) at the Queen's Medical Centre, Nottingham were offered intravitreal triamcinolone.

All eyes had previously undergone macular grid or focal laser treatments, the last of which was at least 3 months prior to the inclusion into the series. Patients' entry was based on the presence of foveal oedema with reduced vision on clinical biomicroscopy. Both phakic or pseudophakic patients were enrolled and written informed consent was obtained. Best-corrected visual acuity (bcva) was assessed on the ETDRS chart before and at each visit at 1,3, and 6 months after the injection. All patients underwent a 78D or fundus contact lens examination by one of the investigators (SAV, AN, CSL), for the presence of clinically significant macular oedema as well as the adequacy of macular laser treatment.

IOP with applanation tonometry was checked before and at each follow-up visit.

A preinjection fluorescein angiogram was performed in patients whose macula showed signs of ischaemia clinically and angiography was repeated during the follow-up, if clinically indicated.

All phakic patients were also assessed on the slit lamp for the presence of any significant lens opacity before the injection and a note made if there was a significant progression during the follow-up period or of any fresh onset of cataractous changes in the lens in those without a pre-existing cataract.

\section{Technique}

All patients received $4 \mathrm{mg}$ of intravitreal triamcinolone through the inferotemporal pars plana. The injection was made $3.5 \mathrm{~mm}$ behind the limbus in pseudophakic patients and $4 \mathrm{~mm}$ in phakic patients. The conjunctiva was anaesthetised with two drops of amethocaine at 5 min interval and a swab stick applied soaked in amethocaine to the planned injection site in those patients who appeared to be more apprehensive. A volume of $5 \%$ betadine drops were applied to the inferior fornix and the lids were cleaned with betadine solution prior to the injection. The injection was made with a $27 \mathrm{G}$ needle mounted on an insulin ( $1 \mathrm{ml}$ ) syringe under direct visual control. After inserting the needle through the pars plana, when the needle tip became visible, the tip was turned to point the bevel posteriorly and the steroid injected very slowly into the mid-posterior vitreous cavity.

Eyes were examined immediately afterwards for the presence of central retinal artery (CRA) pulsations and those with impending obstruction underwent an anterior chamber tap with a $26 \mathrm{G}$ needle mounted on a $1 \mathrm{ml}$ syringe. All eyes were re-examined at $15 \mathrm{~min}$ to half an hour after the injection to measure the IOP and any immediate post-injection complications. Patients were prescribed $\mathrm{G}$ chloramphenicol three times a day for 5 days. Any intra or postinjection complications were noted and patients were examined at 1 week for any serious postinjection complication especially endophthalmitis.

As the department also acquired an Ocular Coherence Tomography (OCT) machine in May 2003, all patients included into the trial from then onwards also underwent retinal thickness measurements on the OCT using the 'fast macular scan' option.

\section{Results}

In all, 29 eyes of 24 patients between the period June 2002 and May 2003 who consented to the procedure received $4 \mathrm{mg}$ of triamcinolone acetonide intravitreally. Only the first eyes of the five patients who eventually underwent bilateral injections were included in the analysis. There were nine left and 15 right eyes and the mean age (SD) of the patients was 65.9 (9.4) years and there were 13 male and 11 female patients. Three eyes were pseudophakic and the remaining were phakic. None of the patients had visually significant lens opacity at the time of injection.

The patients had clinically or angiographically documented macular oedema for an average of 38.2 months (range $=6-120$ months). The average time since the last laser session was 22.0 months (3-108 months) with the mean number of laser treatments before the injection being 2.25 (median $=2.00$, range $=1-5$ ). 
All patients had a minimal follow-up of 1 month and the mean follow-up was $5(+/-3)$ months with a range of 1-12 months. Two eyes required anterior chamber paracentesis at the end of the injection for raised intraocular pressure manifesting as CRA pulsations.

The mean best-corrected $\log$ MAR visual acuity at each follow-up visit and the number of eyes included at each visit are summarised in Table 1 . Overall, 19/23 (83\%) at 1 month, 16/21 (76\%) at 3 months and 6/11 (55\%) at 6 months showed at least some improvement in mean acuity.

Out of the 19 eyes that had best-corrected near vision measurements at 3 months, it had improved at least by one level on the reading test type in 14 eyes (74\%) and had remained stable in the remaining.

The central macular thickness measurements were available for five eyes at 1 month and in one of the eyes at 1 and 3 months. The mean central macular thickness reduced by $23 \%(396-308 \mu \mathrm{m})$ at 1 month and in the one eye with a 3-month reading it reduced further by $40 \%$ (424-251 $\mu \mathrm{m}$ ).

The mean and range of IOPs at each visit are summarised in Table 2 . The IOP rose from baseline value in 61,65 , and $54 \%$ of eyes at 1,3, and 6 months reaching values $>22 \mathrm{mmHg}$ in four, five and two eyes at these visits, respectively (Figure 1). Four eyes required topical antiglaucoma medications for IOPs above $28 \mathrm{mmHg}$ at a mean of 3 months following injection.

One patient required cataract surgery at 7 months after the injection for a clinically significant progression in the cataract and achieved a final best-corrected vision of $6 / 9$ at the last follow-up at 5 months postoperatively. There was no clinically significant progression in the lens opacities of the remaining patients; however, we did not employ any objective lens opacity grading system in the present case series.

One patient who was on warfarin developed a large subconjunctival haematoma at the injection site, which required excision. His vision improved from $6 / 36$ before the injection to $6 / 12$. Three eyes needed repeat injections for the recurrence of macular oedema at an average of 6.7 months after the initial injection.

In the remaining eyes the vision remained stable at last review.

\section{Discussion}

Corticosteroids have been used for treating ocular inflammation for more than 50 years with the intravitreal route providing high intraocular peak concentrations ${ }^{13}$ bypassing the ocular coats. Machemer et $a l^{14}$ first reported intravitreal steroid use to inhibit proliferation of fibroglial cells in proliferative vitreoretinopathy. Beer et $a l^{15}$ reported peak aqueous humour concentrations
Table 1 Mean best-corrected $\log$ MAR visual acuity at each follow up

\begin{tabular}{lcl}
\hline Time, number of eyes & Mean BCVA (SD) & P-value \\
\hline Initial, 24 & $0.72(0.27)$ & \\
1 month, 23 & $0.52(0.20)$ & 0.0002 \\
3 months, 21 & $0.54(0.26)$ & 0.001 \\
6 months, 11 & $0.60(0.28)$ & 0.26 \\
Last follow-up, 24 & $0.55(0.26)$ & 0.01 \\
\hline
\end{tabular}

${ }^{a}$ One patient missed his 1-month appointment.

$P$-values are from the Wilcoxon signed-rank test.

Table 2 IOPs at each follow-up visit with standard errors

\begin{tabular}{lccc}
\hline Time, number of eyes & Mean IOP, $m m H g(S D)$ & Range & P-value \\
\hline Initial, 24 & $17.0(2.7)$ & $10-22$ & \\
1 month, 23 & $19.4(3.8)$ & $14-26$ & 0.009 \\
3 months, 21 & $19.8(4.7)$ & $14-32$ & 0.005 \\
6 months, 11 & $19.7(5.4)$ & $13-30$ & 0.18 \\
Last follow-up, 24 & $19.2(4.6)$ & $13-28$ & 0.07 \\
\hline
\end{tabular}

$P$-values are from the Wilcoxon signed-rank test.

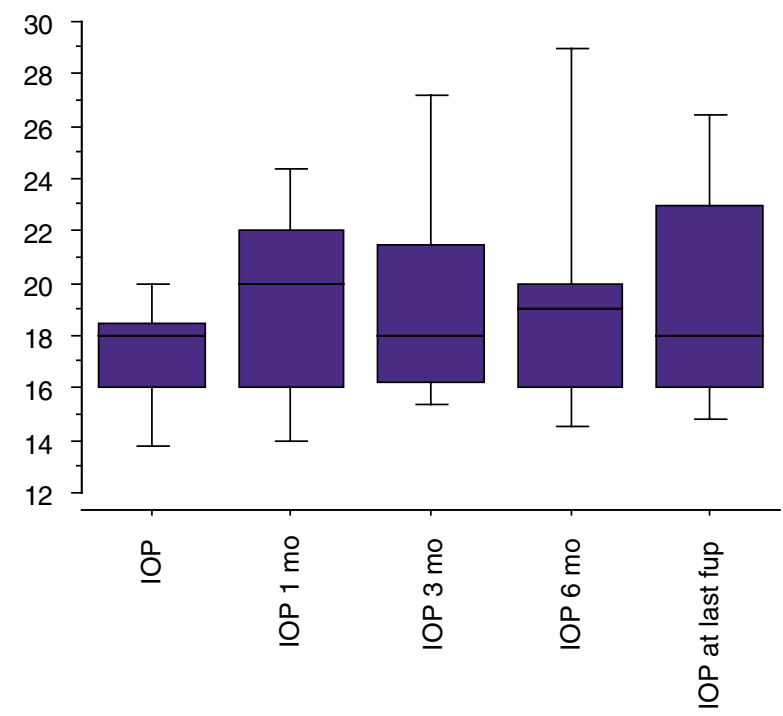

Figure 1 Line chart showing IOPs at each follow-up visit.

ranging from 2151 to $7202 \mathrm{ng} / \mathrm{ml}$ with an elimination half-life of $448 \pm 136 \mathrm{~h}$ in human subjects. They concluded that based upon the five elimination half-lives needed for complete removal of the drug from the eye, in patients without prior vitrectomy, active triamcinolone should persist for 3 months after an injection of $4 \mathrm{mg}$. Early reports have been encouraging in patients with diabetic macular oedema refractory to laser or in those with diffuse macular thickening.

All our patients had long-standing diabetic macular oedema that persisted despite multiple laser treatment 
sessions with visual acuity that had either been slowly deteriorating or had been stable for at least 1 year.

We used the same dose of triamcinolone as Martidis et $a l,{ }_{1}^{11}$ who reported an average improvement of 2.4, 2.4, and 1.3 Snellen lines in their series of 16 patients with macular oedema of 32 months mean duration. Our patients' eyes showed an average improvement of 10 , nine and six letters at 1,3, and 6 months, respectively, on the $\log$ MAR chart which is considered to be a more objective method of visual acuity testing than the Snellen chart. Our group had a slightly longer duration of macular oedema at 38.2 month (mean) and also had had their last laser session at a mean of almost 2 years prior to the intervention. Martidis et al did not comment on the average time since the last laser treatment in their group of patients. However, their patients had a similar number of preinjection laser treatment sessions.

One of the visual function parameters that has not been assessed by previous workers is the effect of triamcinolone injection on the reading vision, which may be predominantly affected in some of the patients with early stages of diabetic maculopathy reducing their quality of life substantially. Best-corrected reading visions improved in 14 of the $19(74 \%)$ eyes at 3 months and in three of these it was noted to have improved despite no improvement in their corresponding distance acuities.

In our prospective case series there were few significant complications of what is an invasive medical treatment. The intraocular pressure exceeded $22 \mathrm{mmHg}$ in four, five, and two eyes at 1,3 , and 6 months rising by an average of $2.4,2.8$, and $2.7 \mathrm{mmHg}$ of $\mathrm{Hg}$ at the same time points, however, only four eyes were considered to require treatment with topical antiglaucoma medications for IOPs above $28 \mathrm{mmHg}$. This is lower than the incidence of ocular hypertension reported by Jonas et al, ${ }^{16}$ who reported IOP elevation of above $21 \mathrm{mmHg}$ in $50 \%$ of their patients at about 1-2 months. It is important to note that Jonas et al used a much higher dose $(25 \mathrm{mg})$ of triamcinolone.

One eye had visually significant progression of cataract and underwent routine phacoemulsification and lens implantation at 7 months postinjection achieving a final acuity of $6 / 9$ showing no worsening of macular oedema in the postoperative follow-up period of 5 months.

There are some recent reports in the literature of both infectious and sterile noninfectious endophthalmitis in patients following injections of triamcinolone. ${ }^{17,18}$ Like Martidis and Jonas et al, we did not encounter this complication in our group of patients, however, only three of our eyes have received a second injection to date. With increasing follow-up, we anticipate a rise in the number of patients requiring repeat injections due to the recurrence of macular oedema. The visual improvement is modest however, in the clinical situation considering the chronicity of the macular oedema and its refractoriness to multiple previous laser treatments, is still clinically significant.

This study is a prospective case series and not a randomised controlled trial however, each eye effectively serves as its own control. One of the strengths of our study is that we measured best-corrected distance and reading acuity utilising standard ETDRS logMAR chart (for distance) at each visit.

We note a slight regression of the effect of treatment at 6 months in some eyes, a feature common to other reports indicating that repeated injections may be required at the $4 \mathrm{mg}$ dosage. Longer follow-up of patients treated to date and a prospective randomised controlled trial is clearly required before this novel method of treating diabetic macular oedema can be deemed 'safe and effective'.

Intravitreal triamcinolone does appear to offer hope for improvement in vision in patients who previously had no other effective treatment options.

\section{References}

1 Early Treatment Diabetic Retinopathy Study design and baseline patient characteristics. ETDRS report number 7 . Ophthalmology 1991; 98(5 Suppl): 741-756.

2 Photocoagulation for diabetic macular edema. Early Treatment Diabetic Retinopathy Study report number 1. Early Treatment Diabetic Retinopathy Study research group. Arch Ophthalmol 1985; 103(12): 1796-1806.

3 Bailey CC, Sparrow JM, Grey RH, Cheng H. The National Diabetic Retinopathy Laser Treatment Audit. III. Clinical outcomes.. Eye 1999; 13( Part 2): 151-159.

4 Schatz H, Madeira D, McDonald HR, Johnson RN. Progressive enlargement of laser scars following grid laser photocoagulation for diffuse diabetic macular oedema. Arch Ophthalmol 1991; 109(11): 1549-1551.

5 Jonas JB, Hayler JK, Panda-Jonas S. Intravitreal injection of crystalline cortisone as adjunctive treatment of proliferative vitreoretinopathy. Br J Ophthalmol 2000; 84: 1064-1067.

6 Challa JK, Gillies MC, Penfold PL, Gyory JF, Hunyor AB, Bison F. Exudative macular degeneration and intravitreal triamcinolone:18 month follow up. Aust NZ J Ophthalmol 1998; 26: 277-281.

7 Karacorlu M, Ozdemir S, Karacorlu S. Intravitreal triamcinolone acetonide for the treatment of chronic pseudophakic cystoid macular oedema. Acta Ophthalmol Scand 2003; 81(6): 648-652.

8 Antcliff RJ, Spalton DJ, Stanford MR, Graham EM, Ffytche TJ, Marshal J. Intravitreal triamcinolone for uveitic cystoid macular oedema: an optical coherence tomography study. Ophthalmology 2001; 108: 765-772.

9 Young S, Larkin G, Branley M, Lightman S. Safety and efficacy of intravitreal triamcinolone for cystoid macular oedema in uveitis. Clin Exp Ophthalmol 2001; 29: 2-6. 
10 Jonas JB, Kreissig I, Söfker A, Degenring RF. Intravitreal injection of triamcinolone acetonide for diabetic macular edema. Arch Ophthalmol 2003; 121: 57-61.

11 Martidis A, Duker JS, Greenberg PB, Rogers AH, Puliafito $\mathrm{CA}$, Reichel $\mathrm{E}$ et al. Intravitreal triamcinolone for refractory diabetic macular oedema. Ophthalmology 2002; 109: 920-927.

12 Jonas JB, Söfker A. Intraocular injection of crystalline cortisone as adjunctive treatment of diabetic macular oedema. Am J Ophthalmol 2001; 132: 425-427.

13 Tano Y, Chandler D, Machemer R. Treatment of intraocular proliferation with intravitreal injection of tramcinolone acetonide. Am J Ophthalmol 1980; 90: 810-816.

14 Machemer R, Sugita G, Tano Y. Treatment of intraocular proliferations with intravitreal steroids. Trans Am Ophthalmol Soc 1979; 77: 171-180.
15 Beer PM, Bakri SJ, Singh RJ, Liu W, Peters GB, Miller M. Intraocular concentration and pharmacokinetics of triamcinolone acetonide after a single intravitreal injection. Ophthalmology 2003; 110(4): 681-686.

16 Jonas JB, Kreissig I, Degenring R. Intraocular pressure after intravitreal injection of triamcinolone acetonide. Br J Ophthalmol 2002; 86: 1450-1451.

17 Roth DB, Chieh J, Spirn MJ, Green SN, Yarian DL, Chaudhry NA. Noninfectious endophthalmitis associated with intravitreal triamcinolone injection. Arch Ophthalmol 2003; 121(9): 1279-1282.

18 Nelson ML, Tennant MT, Sivalingam A, Regillo CD, Belmont JB, Martidis A. Infectious and presumed noninfectious endophthalmitis after intravitreal triamcinolone acetonide injection. Retina 2003; 23(5): 686-691. 